East African Medical Journal Vol. 86 No. 6 June 2009

INTESTINAL POLYPARASITISM IN A RURAL KENYAN COMMUNITY

P.N. Nguhiu, BVM, MSc., Lecturer, Animal Health and Industry Training Institute, P.O. Box 29040-00625, Nairobi, Kenya, H. C. Kariuki, PhD, Research Scientist, Division of Vector Borne Diseases, Ministry of Health, P.O. Box 27250- 00202, Nairobi, Kenya, J. K. Magambo, PhD, Professor, Institute of Tropical Medicine and Infectious Diseases, Jomo Kenyatta University of Agriculture and Technology, P.O. Box 62000 - 00200, Nairobi, Kenya, G. Kimani, PhD, Chief Research Officer, J. K. Mwatha, PhD, Principal Research Officer, Centre for Biotechnology Research and Development, Kenya Medical Research Institute, P.O. Box 54840- 00200, Nairobi, Kenya, E. Muchiri, PhD, Head, Division of Vector Borne Diseases, Ministry of Health Division of Vector Bome Diseases, P.O Box 27250- 00202, Nairobi, Kenya, D. W. Dunne, $\mathrm{PhD}$, Professor, Division of Parasitology, Department of Pathology, University of Cambridge, United Kingdom, B. J. Vennervald, PhD, Professor, DBL- Centre for Health Research and Development, Department of Pathology, Faculty of Life Sciences, University of Copenhagen, Thorvaldsensvej 57 DK-1871, Frederiksberg C Denmark and G.M. Mkoji, PhD, Chief Research Officer and Director, Centre for Biotechnology and Development, Kenya Medical Research Institute, P.O. Box 54840- 00200, Nairobi, Kenya

Request for reprints to: Dr. P.N. Nguhiu, Animal Health and Industry Training Institute, P.O. Box 29040- 00625, Nairobi, Kenya

\title{
INTESTINAL POLYPARASITISM IN A RURAL KENYAN COMMUNITY
}

\author{
P. N. NGUHIU, H. C. KARIUKI, J. K. MAGAMBO, G. KIMANI, J. K. MWATHA, E. MUCHIRI, \\ D.W. DUNNE, B. J. VENNERVALD and G.M. MKOJI
}

\begin{abstract}
Background: Polyparasitism seems to be a common feature in human populations in sub-Saharan Africa. However, very little is known about its epidemiological significance, its long term impact on human health or the types of interactions that occur between the different parasite species involved.

Objectives: To determine the prevalence and co-occurrence of intestinal parasites in a rural community in the Kibwezi, Makueni district, Kenya.

Design: A cross sectional study.

Setting: Kiteng'ei village, Kibwezi, Makueni district, between May and September 2006.

Subjects: One thousand and forty five who comprised of 263 adult males, 271 adult females $>15$ years of age and 232 boys, and 279 girls $<15$ years of age.

Interventions: All infected members of the community were offered Praziquantel (at dosages of $40 \mathrm{mg} / \mathrm{kg}$ body weight) for Schistosomiasis and Albendazole $(600 \mathrm{mg})$ for soil transmitted helminths.

Results: A total of ten intestinal parasite species (five protozoan and five helminth parasite species) were present in this community and polyparasitsm was common in individuals 5- 24 years of age with no gendar related differences. Most of the infections were mild. The protozoan parasites of public health significance present were Entamoeba histolytica and Giardia lamblia with prevalence of $12.6 \%$ and $4.2 \%$, respectively. The helminth parasites of public health significance in the locality were Schistosoma mansoni with a prevalence of $28 \%$, and hookworms prevalence of $10 \%$. About $53 \%$ of the study population harboured intestinal parasite infections, with $31 \%$ of the infected population carrying single parasite species infections, and $22 \%$ harbouring two or more intestinal parasite species per individual. Significant positive associations ( $\mathrm{p}$ values $<0.05$ ) were observed between $S$. mansoni and hookworms, hookworms and Hymenolepis. nana and Entamoeba histolytica and Entamoeba coli. Conclusion: Intestinal polyparasitism was common in the Kiteng'ei community, particularly in individuals aged of 5-24 years old. An integrated control programme of approach would be recommended for the control of S. mansoni, hookworms and Entamoeba histolytica for this community.
\end{abstract}




\section{INTRODUCTION}

Polyparasitism is a common phenomenon worldwide, and while its effects are often clinically inapparent, multiple parasite species infections may exacerbate clinical manifestations (1). For example, malaria parasites, intestinal helminths and protozoan may co-exist in an individual causing micro-nutrient deficiencies, anaemia, and contribute to retarded growth and development (2). Co-occurrence of schistosomiasis and filariasis in an individual may also result in retarded growth and development (2). Overall, individuals with multiple parasite infections are often at an elevated risk of morbidity (3). Intestinal parasiticinfections are common in sub-Saharan Africa and often multiple parasite species involving both helminths and protozoans may occur in an individual (4-7). Children are the most commonly infected and the parasite species involved include Entamoeba histolytica, Giardia lamblia and Cryptosporidia (all protozoans) and hookworms, Ascaris lumbricoides and Trichuris trichiura (helminths), $(4,5,8,9)$.

The global burden of disease caused by the three major intestinal nematodes (hookworms, Ascaris lumbricoides and Trichuris trichiura) is estimated at 22.1 million disability adjusted life years (DALYs) lost to hookworm, 10.5 million for A. lumbricoides and 6.4 million for T. trichiura (2). The combined burden of infection is estimated to exceed 1000 million infected persons with Ascaris lumbricoides, hookworm (Ancylostomum duodenale and Necator americanus), and T. trichiura (7).

Three major intestinal helminths namely, hookworms, Trichuris and Ascaris, hookworm is the most important public health problem with an estimated 1.3 billion people infected worldwide (10) and often associated with iron deficiency anaemia (11). Hookworm infections frequently co-occur with A. lumbricoides and T. trichiura and comprise the major soil transmitted helminths (7). The World Health Organization $(\mathrm{WHO})$ has estimated that schistosomiasis and soil-transmitted helminth infections represent $40 \%$ of the disease burden due to all tropical diseases excluding malaria (12). Giardiasis, with an estimated 200 million people infected, is most common in children aged one to five years old, and in severe cases may be associated with acute and persistent diarrhoea, malabsorption of nutrients and impairment of children's growth and development (8).

Intestinal polyparasitism is common in Kenya $(8,13-15)$. The effects of polyparasitism in children may include wasting, stunting, decreased physical fitness and activity, decreased cognitive development and performance, decreased work performance capacity and productivity, and increased school and work absenteeism; and in adults its effects include decreased fitness, cognition, activity, performance, work capacity and productivity, increased maternal and foetal morbidity and death (3). The purpose of the present study was to assess the extent of intestinal polyparasitism as a measure of disease burden in a rural community based in Kiteng'ei village, Kibwezi area, Kenya, in preparation for an integrated intervention programme targeting schistosomiasis and intestinal parasitic infections. In addition, gender and age were investigated as factors in polyparasitism, and the association between the different parasite species involved determined.

\section{MATERIALS AND METHODS}

Study area and study population: This study was conducted in Kiteng'ei village, Kambu location in the Kibwezi, Makueni District which lies between longitude $38^{\circ}-38.2^{\circ}$ East and latitude $2.1^{\circ}-2.3^{\circ}$ South of the Equator, and located approximatel $250 \mathrm{~km}$ south east of Nairobi. The village is located along the Kambu river, a seasonal stream which is a tributary of the Athi River complex. The demographic information obtained for the study village included number of households, number of persons in each homestead and age/ sex of each study individual. Each study individual was given a unique identification number.

Faecal sample collection and laboratory procedures: This was a cross- sectional study, carried out from May to September 2006, and involved the entire population of Kiteng'ei. A single faecal sample was collected from each enrolled and consenting individual in an individual specimen container and processed for parasitological examination by microscopy. Faecal specimens were examined for both protozoan and helminth parasite species. A single Kato-Katz thick faecal smear was prepared from each stool sample essentially as described by Carter and Lema (16) for the detection of schistosomes and helminth ova, and the formol-ether wet faecal smear was prepared for detection of intestinal protozoan cysts as described by Carter and Lema (16). The smears were examined for presence of parasite ova or cysts by microscopy, but only Schistosoma mansoni ova were quantified.

Treatment of infected individuals: All the individuals diagnosed to have intestinal protozoan infections were given metronidiazole $\left(\right.$ Flagyl $\left.{ }^{\mathrm{R}}\right)$, standard adult dose $750 \mathrm{mg}$ (by oral administration) three times a day (tid) for five days and standard paediatric dose of 10-15 $\mathrm{mg} / \mathrm{kg}$ body weight tid for five days, and those found to have schistosome infection received a standard oral dose of praziquantel ( $40 \mathrm{mg} / \mathrm{kg}$ body weight). Those infected with intestinal helminth infections received albendazole $(600 \mathrm{mg})$ as recommended by the WHO (12). 
Data analyses: Demographic and parasitological data were entered into a computer for storage and subsequent analysis. The SPSS-PC version 11.0 (SPSS Chicago Illinois) computer software was used for data handling and analysis. Frequency distribution of variables was performed to illustrate the prevalence of the intestinal protozoan and helminth parasite species. Chi squared test $\left(\mathrm{X}^{2}\right)$ was done to compare proportions. Univariate statistics were applied to assess the influence of age or sex on infection status. Cross tabulations were performed to compare (prevalence or intensity) between males and females for Entamoeba coli, Entamoeba histolytica, I.butschlii, S. mansoni and hookworms. The association between parasite species was examined by using $2 \times 2$ contingency tables. The Chi- Squared test at 95\% confidence interval with one degree of freedom and 5\% significance level were done to show the differences in parasite pairs. In a second step, logistic regression modeling techniques were applied to assess significant association between a particular intestinal parasite and sex, age group and another intestinal parasite. For each parasite, a baseline model was established with infected study participants defined as cases. Sex, age group and infection status with intestinal parasites were all incorporated into the model. Non significant associations ( $p>0.05)$ were removed. The odds ratio (OR) including 95\% confidence interval (CI) and corresponding P-values were calculated for the associations that were significant. Measurements of association between the different parasite species was performed using Pearson's Correlation (17). Multivariate analysis was performed to show associations between the different species of parasites.

Study approvals: This study was undertaken with the approval of both the scientific and ethical review committees of the Kenya Medical Research Institute (KEMRI). The project was presented and explained to the community through a Chiefs baraza and informed consent was obtained from the adults (18 years of age and above) and from parents / guardians of participating children $(<18$ years old), before stool specimens were obtained from individuals for parasitological examination.

\section{RESULTS}

Intestinal parasite infections in the Kiteng 'ei Community: There were 295 households in the Kiteng'ei village with a total population of 1785 individuals (comprising 898 males and 887 females). A total of 1045 individuals who included 511 children and 534 adults were examined for intestinal parasites. Both protozoan and helminth parasites were present in the community, and a total of ten parasite species were identified under a microscope based on presence of characteristic cysts (for protozoa) or ova (for helminths) in the faecal specimens (Table 1).

Table 1

Sex-related differences in the prevalence of intestinal protozoan parasites, Schistosoma mansoni and soiltransmitted helminths in the Kiteng'ei Community of Kambu, Kibwezi, Makueni District, Kenya

\begin{tabular}{lcccc}
\hline Intestinal parasite & Overall prevalence & Male & Females & P-value * \\
species encountered & $(\mathrm{n}=1045)$ & $(\mathrm{n}=508)$ & $(\mathrm{n}=537)$ & No. $(\%)$ \\
& No. $(\%)$ & No. $(\%)$ & \\
\hline
\end{tabular}

\begin{tabular}{|c|c|c|c|c|c|c|c|}
\hline \multicolumn{8}{|l|}{ A Protozoan parasite } \\
\hline Entamoeba coli & 174 & 16.7 & 87 & 17.1 & 87 & 162 & $>0.001$ \\
\hline Entamoeba histolytical & 132 & 12.6 & 76 & 15.0 & 56 & 10.4 & $<0.01$ \\
\hline Entamoeba dispar & & & & & & & \\
\hline Iodamoeba butschlii & 63 & 6.0 & 25 & 4.9 & 38 & 7.1 & $<0.025$ \\
\hline Giardia lamblia & 44 & 4.2 & 18 & 3.5 & 26 & 4.8 & $>0.001$ \\
\hline Endolimax nana & 17 & 1.6 & 10 & 2.0 & 7 & 1.3 & $<0.025$ \\
\hline \multicolumn{8}{|l|}{ B Helminth parasites } \\
\hline Schistosoma mansoni & 291 & 28 & 167 & 32.9 & 124 & 23.1 & $<0.025$ \\
\hline Hookworm & 108 & 10.3 & 55 & 10.2 & 53 & 9.9 & $>0.005$ \\
\hline Hymenolepis nana & 3 & 0.3 & 1 & 0.2 & 2 & 0.4 & $<0.005$ \\
\hline Trichiuris trichiura & 2 & 0.2 & 0 & 0 & 2 & 0.4 & $>0.005$ \\
\hline Ascaris lumbricoides & 1 & 0.1 & 0 & 0 & 1 & 0.2 & $>0.005$ \\
\hline
\end{tabular}

* Tested using Chi-squared $\left(X^{2}\right)$, P-values of 0.05 and below were considered statistically significant. 
Of the 1045 individuals examined, 53.4\% harboured at least one parasite species, with $41 \%$ harbouring protozoan infections and 39 helminth infections. The most common protozoa present in the Kiteng'ei community were Entamoeba coli with a prevalence of 17\% and Entamoeba histolytica/ Entamoeba dispar a pathogen that causes diarrhoea (prevalence 13\%), and Giardia lamblia common intestinal flagellate (prevalence 4\%). Other protozoan parasites present in the community were Iodamoeba butschlii $(6 \%)$ and Endolimax nana (2\%). Of the parasitic protozoans present, Entamoeba histolytica and G. lamblia are considered to be of public health significance. Interestingly, significantly more males $(7.3 \%)$ than females $(5.4 \%)$ harboured Entamoeba histolytica, infections whereas no gender related differences in prevalence were observed for Entamoeba coli. Protozoan infections were present across all age groups, with peak prevalences occurring in individuals in the 5-14 years and 15-24 year age groups (Table 2).

The most common helminth infections in this community were Schistosoma mansoni (prevalence $28 \%$ ) and hookworms (10.3\%) (Table 1). Other helminth parasites present were Hymenolepis nana, Trichuris trichiura and Ascaris lumbricoides, but their prevalences were less than $0.5 \%$. With respect to $S$. mansoni infection, the proportion of males $(16 \%)$ infected was significantly greater than the females (12\%), $\quad \mathrm{P}<0.025$. However, no gender related difference in prevalence was observed in hookworm infections. Overall, S. mansoni infections were most common in individuals aged 24 years and below, whereas hookworm infections were most common in older individuals (Table 2).

Multipleparasite infections: Multiple parasiteinfections (Polyparasitism) were recorded in 22\% of the study population. Majority of those with multiple parasite infections $(21.4 \%)$ had two to three parasite species per individual, and only $0.6 \%$ harboured four parasites. Of the 173 individuals harbouring two parasite species, $114(65.9 \%)$ had both protozoan and helminth parasite species while $48(27.7 \%)$ had protozoan parasite species, and $11(6 \%)$ had helminth parasite infections only. Of the 43 individuals habouring three parasite species infections, $24(55.8 \%)$ of the individuals harboured two protozoan and one helminth parasite species, $14(32.6 \%)$ of the individuals had two; one protozoan and two helminth parasite species, and only five $(11.6 \%)$ of the individuals harboured three protozoan parasite species. Interestingly, none of the study individuals harboured threehelminth parasites concurrently. In general, intestinal protozoan parasite infections occurred across all the age groups in the study population, but most of the helminth parasite infections occurred in the younger age groups $(<24$ years old). The prevalence of polyparasitism was apparently not gender related (Figure 1) but was age-related, being most prevalent in individuals in the 5-14 year age group (Figure 2).

Table 2

Prevalence of intestinal parasite infections by host age in the Kiteng'ei Community of Kambu, Kibwezi area in Makueni District, Kenya

\begin{tabular}{|c|c|c|c|c|c|c|c|c|c|c|c|c|}
\hline \multirow{3}{*}{ Parasite Species } & \multicolumn{10}{|c|}{ Age group in years } & \multirow{2}{*}{\multicolumn{2}{|c|}{$\geq 45(\mathrm{n}=174)$}} \\
\hline & \multicolumn{2}{|c|}{$<5(\mathrm{n}=173)$} & \multirow{2}{*}{\multicolumn{2}{|c|}{$\begin{array}{c}5-14 \quad(\mathrm{n}=338) \\
\text { No. } \quad(\%)\end{array}$}} & \multirow{2}{*}{$\begin{array}{c}15-24 \\
\text { No. }\end{array}$} & \multirow{2}{*}{$\begin{array}{c}(\mathrm{n}=199) \\
(\%)\end{array}$} & \multirow{2}{*}{$\begin{array}{c}25-34 \\
\text { No. }\end{array}$} & \multirow{2}{*}{$\begin{array}{c}(\mathrm{n}=92) \\
(\%)\end{array}$} & \multirow{2}{*}{$\begin{array}{l}35-44 \\
\text { No. }\end{array}$} & \multirow{2}{*}{$\begin{array}{r}\mathrm{n}=69 \\
(\%)\end{array}$} & & \\
\hline & No. & $(\%)$ & & & & & & & & & No. & $\begin{array}{c}(\mathrm{n}=174) \\
(\%)\end{array}$ \\
\hline E. coli & 14 & 8.1 & 43 & 12.7 & 41 & 20.6 & 17 & 18.5 & 12 & 17.4 & 47 & 27.0 \\
\hline E. histolytical & 10 & 5.8 & 51 & 15.1 & 30 & 15.1 & 12 & 13.0 & 7 & 10.1 & 22 & 12.6 \\
\hline \multicolumn{13}{|l|}{ E. dispar } \\
\hline I. butschlii & 3 & 1.7 & 21 & 6.2 & 20 & 10.0 & 4 & 4.3 & 6 & 8.6 & 9 & 5.2 \\
\hline G. lamblia & 8 & 4.6 & 14 & 4.1 & 10 & 5.0 & 3 & 3.3 & 3 & 4.3 & 6 & 3.4 \\
\hline E. nana & 4 & 2.3 & 3 & 0.9 & 4 & 2.0 & 3 & 3.3 & 0 & 0 & 3 & 1.7 \\
\hline S. mansoni & 8 & 24.6 & 112 & 33.1 & 103 & 51.8 & 23 & 25.0 & 15 & 21.4 & 30 & 17.2 \\
\hline Hookworm & 3 & 1.7 & 25 & 7.4 & 31 & 15.6 & 7 & 7.6 & 13 & 18.8 & 29 & 16.7 \\
\hline H. nana & 0 & 0 & 2 & 0.6 & 1 & 0.5 & 0 & 0 & 0 & 0 & 0 & 0 \\
\hline Tr. Trichiura & 1 & 0.6 & 1 & 0.3 & 0 & 0 & 0 & 0 & 0 & 0 & 0 & 0 \\
\hline A. lumbricoides & 1 & 100 & 0 & 0 & 0 & 0 & 0 & 0 & 0 & 0 & 0 & 0 \\
\hline
\end{tabular}


Figure 1

Prevalence of single and multiple parasite species infections in the Kiteng'ei community of Kambu, Kibwezi, Makueni district, Kenya by gender

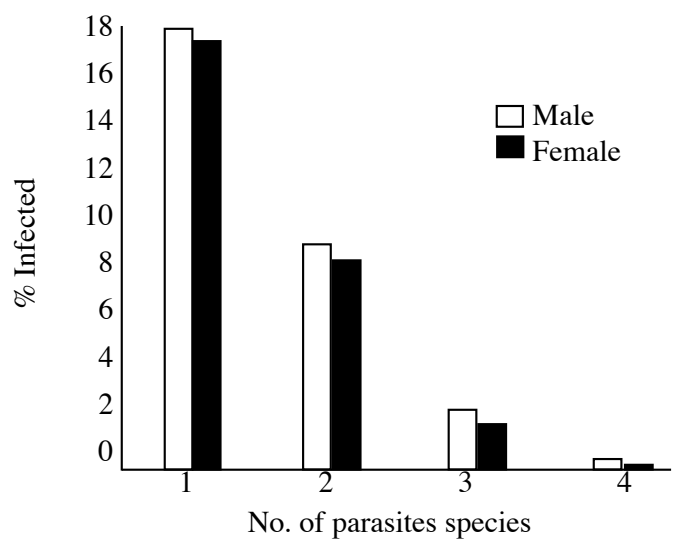

Figure 2

Prevalence of polyparasitism in Kiteng'ei community of Kambu, Kibwezi, district, Kenya in relation to age groups

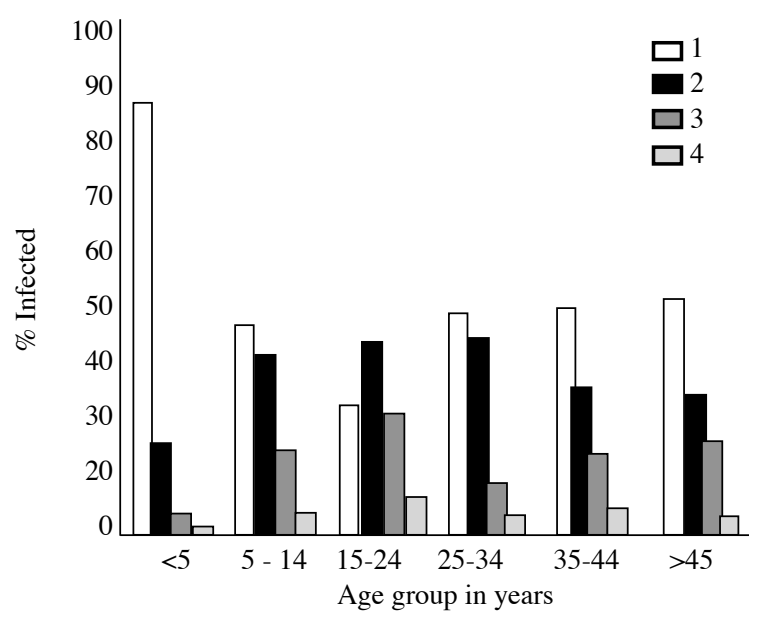

Association between parasite species: Both positive and negative associations were observed for parasite species present in the Kiteng'ei community. Significant positive associations were observed between protozoan species, between helminth and protozoa species, and between helminth species (Table 3). Although Schistosoma mansoni was the most common parasite species in the community, it was not associated with the occurrence of other parasites, and only a marginal association was observed between Schistosoma mansoni and hookworm infections. Statistically significant pairwise interactions were observed between Entamoeba histolytica/ Entamoeba coli and hookworms / Entamoeba coli. Similarly, negative associations were observed between protozoan and helminth species. However, these associations were not statistically significant by Pearson's correlation coefficient (r) analysis.

The risk estimator (Odds Ratio): Given one parasite species, the estimation of the measure of the odds of being infected to non-infected by the particular parasite species was calculated at $95 \%$ confidence interval and 5\% significant for the different parasite pairs. The presence of hookworm was a risk for the occurrence of Hymenolepis nana, with odds ratio of 17.66. Other parasite pairs which had high odds ratio were: Endolimax nana with Iodomoeba butschlii (6.968), Entamoebacoli with Iodomoebabutshclii (6.106), and Entamoeba coli with Endolimax nana (5.884). The presence of $S$. mansoni which was the most prevalent parasite was not associated with the occurrence of other parasites.

Table 3

Positive associations between intestinal parasite species present in the Kiteng'ei Community of Kambu, Kibwezi area in Makueni District, Kenya

\begin{tabular}{lcccc}
\hline Parasite pair & $\begin{array}{c}\text { Pearson's } \\
\text { R-value }\end{array}$ & $\begin{array}{c}\text { Significance } \\
\text { test }\end{array}$ & $\begin{array}{c}\text { Odds ratio } \\
(95 \% \mathrm{CI})\end{array}$ & P-value* \\
\hline $\begin{array}{l}\text { S. mansoni versus } \\
\begin{array}{l}\text { Hookworm } \\
\text { A. lumbricoides }\end{array}\end{array}$ & 0.021 & 0.0507 & $1.56(0.75,1.79)$ & 0.046 \\
$\begin{array}{l}\text { versus E. coli } \\
\text { Hookworm versus }\end{array}$ & 0.069 & 0.025 & $0.17(0.15,0.99)$ & 0.035 \\
$\begin{array}{l}\text { H. nana } \\
\begin{array}{l}\text { Hookworm versus } \\
\text { E.coli }\end{array}\end{array}$ & 0.099 & 0.001 & $17.7(1.6,196.4)$ & 0.001 \\
$\begin{array}{l}\text { E. histolytica } \\
\text { nis }\end{array}$ & 0.152 & 0.000 & $2.9(1.9,4.5)$ & $<0.001$ \\
& 0.108 & 0.000 & $2.1(1.4,3.2)$ & $<0.001$
\end{tabular}


versus E. coli

\begin{tabular}{|c|c|c|c|c|}
\hline E.coli versus & 0.125 & 0.000 & $5.9(2.2,15.50$ & $<0.001$ \\
\hline \multicolumn{5}{|l|}{ E. nana } \\
\hline E. coli versus & 0.232 & 0.000 & $6.1(3.6,10.3)$ & $<0.001$ \\
\hline \multicolumn{5}{|l|}{ I. butschlii } \\
\hline E. nana versus & 0.126 & 0.000 & $7.0(2.4,20.4)$ & $<0.001$ \\
\hline \multicolumn{5}{|l|}{ I. butschlii } \\
\hline Hookworm versus & 0.083 & 0.055 & $2.0(1.0,3.8)$ & 0.055 \\
\hline
\end{tabular}

I. butschlii

* P- values of 0.05 and below were considered statistically significant

\section{DISCUSSION}

In the presentstudy, the prevalence of intestinal parasites was examined in a rural community living in Kiteng' ei villagein theKibweziarea. Thisinformationisimportant for a rationale design and implementation of a sound control programme. Intestinal protozoan parasites, Schistosoma mansoni, and soil transmitted helminths are endemic in the Kiteng'ei community. Polyparasitism was common in the community and accounted for $22 \%$ of the parasite infections. Previous studies on intestinal parasites in Kenya considered specific groups mostly school children and focused primarily on helminth parasite infections $(14,15)$. The current study investigated both helminth and protozoan parasites, across a community comprising both children and adults. The results of the current study are comparable with those of previous studies with respect to intestinal parasite infections in Kenya (18).

The results of the present study were obtained from a cross-sectional survey of a population of 1045 individuals. Diagnosis of the intestinal parasites was based on both the Kato-Katz and formol-ether faecal processing techniques on a single faecal sample per individual. The combined faecal processing techniques improved the detection of hookworms in particular, whose detection becomes difficult beyond 30 to 60 minutes on Kato - Katz slide preparation. Detection of intestinal protozoan parasites relied on a single formolether processed faecal samples and parasites were scored as present or absent. The weakness of relying on singlefaecal sample versus the conventional three stool samples is that intestinal parasites are shed in stools intermittently, hence reliance on single sample may miss some parasites and hencelead tounderestimation of parasite prevalence $(4,8)$. However, a stochastic model for egg count variation which incorporates the distribution of worms and worm pairs in the population has been developed (19). A pocket chart for estimating the true Schistosoma mansoni prevalence for each combination of observed prevalence and geometrical mean of positive egg counts has been developed and validated (20). Using this model, and our observed single stool survey prevalence of $28 \%$, the predicted true prevalence from the pocket chart is $50 \%$. The cost of collection and processing of three stool samples per individual in a community surveillance may be too high hence prohibitive in terms of resources. The drop out rates in experiments involving communities may be as high as $30 \%$ hence a very large community may need to be sampled to ensure the correct sample size.

Inourstudy, weobserved presenceoffiveprotozoan and fivehelminth parasite species with $22 \%$ of the study population harbouring two or more parasite species and was most common in individuals below 24 years of age. For parasites of medical significance, intestinal protozoan parasites (primarily Entamoeba histolytica), S. mansoni, and geohelminths (primarily hookworms) were fairly common in the study population. Our observations arein agreement with otherstudiescarried out in Kenya $(8,13)$ and other parts of sub-Saharan Africa $(6,20)$ that have demonstrated that the multiple parasite species infections are the norm rather than the exception. Presence of multiple parasite species in an individual may be associated with severe morbidity and complication $(4,11)$. Therefore, any control initiative that targets only a single parasite species may not be effective in reducing morbidity due to intestinal parasitic infections. An integrated approach targeting the major parasite species present is recommended for this community.

The current study confirms a significant positive association found between S. mansoni and hookworm infections (21). The $5-14$ year age group with higher infection intensities of $S$. mansoni are at higher risk of concurrent hookworm infection. The interactions are likely to be ecological in nature, largely explained by lack of water and sanitation (21). S. mansoni, though the most commonly occurring helminth did not have significant positive associations with other parasite species. In the present study, there was consistent evidence for strong positive association between certain parasite species especially between the various species of amoeba. For example Entamoeba histolytica and Entamoeba coli were associated, consistently. This is consistent with findings in other studies $(1,4)$. In the current study, there were positive associations between Entamoeba coli and hookworms, E. histolytica and E. nana, I. Butschlii and $A$. lumbricoides. These associations suggest that factors that increase the likelihood of infection, for one' species are shared by others. Positive associations observed among different pathogenic parasites may be of clinical significance and may result in aggravated 
morbidity in the infected individual. Although E. coli is a non pathogenic protozoan, its co-infection could influence morbidity caused by the other parasites (1). The positive association between E. coli and E. histolytica is in agreement with previous studies conducted in Kenya (8) and other tropical countries (4).

Negative parasite associations were observed between different intestinal parasites with Giardia lambliaindicating that G. lambliaisnegatively correlated with the occurrence of other intestinal parasites. This has also been observed in other studies $(8,22)$. Clinical giardiasis is usually most prevalent in young age groups, which was confirmed in this study.

In conclusion, intestinal polyparasite infections were common in Kiteng' ei community affecting $22 \%$ of the study population and most common in individuals in the 5- 24 year age group. These estimates were based on a single stool examination, so the actual prevalence will be even higher. There were nogender related differences in prevalence of multiple parasite infections in the study population. From publichealth view point, the parasites that deserve attention in this community are Entamoeba histolytica and $S$. mansoni and an intervention strategy that targets these parasites is recommended for this community.

\section{ACKNOWLEDGEMENTS}

To the community of Kiteng'ei village for their participation in the present study. The help of the field and laboratory staff of the Division of Vector Borne Diseases (DVBD) and Kenya Medical Research Institute (KEMRI), based at Mtito Andei is much appreciated. This research was carried with the permission of the Director, KEMRI.

\section{REFERENCES}

1. Kuesch, G.T. and Migasena, P. Biological implications of polyparasitism. Review Infect. Dis. 1982; 11: 880882.

2. Stephenson, L.S., Latham, M.C. and Ottesen, E.A. Malnutrition and parasitic helminth infections. Parasitology. 2000; 121: S23- S38.

3. Holland, C.V. Hookworm infection. In: Impact of Helminth infections on Human Nutrition. (Stephenson L.S. and Holland C.V.) 1987. pp 128-168. London and Philadelphia. Taylor and Francis Ltd.

4. Buck, A.A., Anderson, R.I. and MacRae, A.A. Epidemiology of parasitism 1.Occurrence, frequency and distribution of multiple infections in rural communities in Chad, Peru, Afghanistan and Zaire. Tropical Med. Paras. 1978; 29: 61-70.

5. World Health Organization (WHO). Intestinal Protozoan and Helminthic Infections. Report of a World Health Organization Scientific group. WHO Technical report Series No, 6666. Geneva, World Health Organization 1981.

6. Magambo, J.K., Zeyhle, E. and Wachira, T.M. Prevalence of intestinal parasites among children in Southern Sudan. East Afr. Med. J. 1998; 75: 288-290.
7. Savioli, L., Stansfield, S, Bundy D.A.P. et al. Schistosomiasis and soil transmitted helminth infection: forging control efforts. Trans. Royal Society Trop. Med. Hygiene. 2002; 96: 577-579.

8. Chunge, R.N., Karumba, P.N., Nagelkerke, N., et al. Intestinal parasites in a rural community in Kenya: Cross-sectional surveys with emphasis on prevalence, incidence, duration of infection, and polyparasitism. East Afr. Med. J. 1991; 68: 112-123.

9. Quihui-Cota, L., Valencia, M.E., Crompton, D.W., et al. Prevalence and intensity of intestinal parasitic infections in relation to nutritional status in Mexican schoolchildren. Trans. Royal Soc. Trop. Med. Hygiene. 2004; 98: 653-659.

10. Crompton, D.W.T. How much helminthiasis is there in the world? J. Parasit. 1999; 85: 397- 403.

11. Chan, M.S., Medley, G.F., Jamieson, D.K. and Bundy, D.A.P. The evaluation of potential global morbidity attributable to intestinal nematode infections. Parasitology. 1994; 109: 373-387.

12. World Health Organization(WHO), 2002. First report of joint WHO expert committees on the prevention and control of Schistosomiasis and soil- transmitted Helminthiasis. Technical ReportSeries, Geneva. WHO Tech. Rep. Ser. 2002; No. 912: 1- 57.

13. Iseki, M., Hayashi, K., ArapSiongok, T.K. and Gatika, S.M. Survey on the prevalence of intestinal protozoa in Naivasha, Kitui, Machakos, Taveta and Nandi Hills areas in Kenya.In:Diseases of the Tropics. Proceedings of the 2nd Annual Medical Science Conference., Nairobi. 1983. Edited by Tukei P.M. and Njogu A.R. pp $197-199$.

14. Thiong'o, F.W., Luoba, A. and Ouma, J.H. Intestinal helminths and schistosomiasis among school children in a moral district in Kenya. East Afr. Med. J. 2001; 78: 279-282.

15. Handzel, T., Karanja, D.M.S., Addiss, D.G., et al. Geographic distribution of schistosomiasis and soil transmitted helminths in Western Kenya:Implications for anthelminthic mass treatment. Am. J. Trop. Med. Hygiene. 2003; 69: 318-323.

16. Carter, J.Y. and Lema, O.E. Examination of Stools. In: A Practical Laboratory Manual for Health Centres in Eastern Africa. AMREF Publishing Department. 1994, pp 169 - 212.

17. Kirkwood, B.R, Essentials of Medical Statistics 1st Edition Oxford Blackwell Scientific Publications. 1998, pp 87-93, 155, 167-171, 191-194.

18. Brooker, S., Miguel, E.A., Moulins, S., et al. Epidemiology of single and multiple species of helminth infections among school children in Busia District, Kenya. East Afr. Med. J. 2000; 77: 157-161.

19. De Vias, S.J., Gryseels, B., Van Oortmarssen, G.J., et al. A pocket chart to estimate true Schistosoma mansoni prevalence. Parasitology Today. 1993; 9: 305-306.

20. De Vias, S.J., Engels, D., Rabello, A.L.T., et al. Validation of a chart to estimate true Schistosoma mansoni prevalences from simple egg counts. Parasitology. 1997; 114: 113-121.

21. Keiser, J., N'Goran, E.K., Traore, M., et al. Polyparasitism with Schistosoma mansoni, geohelminths, and intestinal protozoa in rural Cote d'Ivoire. J. Parasitology. 2002; 88: 461-466.

22. Annan, A., Compton, D.W.T., Walters, D.E. and Arnold, S.E. An investigation of the prevalence of intestinal parasites in preschool children in Ghana. Parasitology. 1986; 92: 209-217. 